\title{
Landscape effects on the abundance and larval diet of the polyphagous pest Helicoverpa armigera in cotton fields in North Benin
}

\author{
Noelline Tsafack, ${ }^{\mathrm{a}, \mathrm{b}^{*}}$ Audrey Alignier, ${ }^{\mathrm{c}}$ Graham P Head, ${ }^{\mathrm{d}}$ Jae H Kim, ${ }^{\mathrm{d}}$ \\ Michel Goulard, ${ }^{\mathrm{e}}$ Philippe Menozzi ${ }^{\mathrm{b}}$ and Annie Ouin ${ }^{\mathrm{a}}$
}

\begin{abstract}
BACKGROUND: The noctuid Helicoverpa armigera is one of the key cotton pests in the Old World. One possible pest regulation method may be the management of host crop in the landscapes. For polyphagous pests such as $H$. armigera, crop diversity and rotations can offer sequential and alternate resources that may enhance abundance. We explore the impact of landscape composition and host crop diversity on the abundance and natal host plant use of $H$. armigera in northern Benin.

RESULTS: Host plant diversity at the largest scale examined (500 m diameter) was positively correlated with $\boldsymbol{H}$. armigera abundance. Host plant diversity and the cover of tomato crops were the most important variables in relation to high abundance of $\boldsymbol{H}$. armigera. Host plant (cotton, maize, tomato, sorghum) proportions and $\mathrm{C}_{3}$ versus $\mathrm{C}_{4}$ plants did not consistently correlate positively with $H$. armigera abundance. Moth proportion derived from cotton-fed larvae was low, $15 \%$ in 2011 and $11 \%$ in 2012 , and not significantly related to $H$. armigera abundance.
\end{abstract}

CONCLUSION: Cotton crop cover was not significantly related to $H$. armigera abundance and may be considered as a sink crop. Landscape composition and sequential availability of host plants should be considered as keys factors for further studies on $\boldsymbol{H}$. armigera regulation.

(C) 2015 Society of Chemical Industry

Supporting information may be found in the online version of this article.

Keywords: moth; natal host plant use; carbon isotope; gossypol; GLM-PLS

\section{INTRODUCTION}

The proportion and arrangement of crops and natural vegetation across the landscape has been proposed as an alternative or at least as a complement to reduce insecticide treatments and achieve biological pest control. ${ }^{1-6}$ Indeed, landscape diversity has been shown to increase the population of natural enemies, ${ }^{7}$ with a positive feedback on pest regulation. ${ }^{8}$ However, other studies have found that landscape diversity plays a more ambivalent role. For example, previous studies showed that landscape diversity enhances not only large-scale aphid parasitism but also aphid populations, ${ }^{9}$ and that landscape diversity had a positive effect both on pollen beetle abundance and parasitism rates. ${ }^{10}$ Most of the studies on pest control by landscape diversity have concentrated on monophagous pests. ${ }^{11,12}$

Few have considered polyphagous pests, which may react to landscape diversity in different ways. It has been shown that cotton pest Helicoverpa armigera was more abundant in cotton fields found in a complex landscape than in a simple landscape. ${ }^{13}$ In complex landscapes, diversity in host plants can offer successive resources that may foster pests at the landscape level but also reduce pest density of a specific crop at the field level. ${ }^{14}$ The main scientific challenges for mobile pests using multiple host plants lies in tracking their successive use of host plants by determining the natal origin of the adults. Stable isotopes have previously been used to identify natal origin in studies of insect migration ${ }^{15}$ and natal host plant use. ${ }^{16}$ Biochemical markers can also be used, ${ }^{17}$ as the analysis of gossypol residues in adult $H$. zea tissues showed that the majority of bollworm moths caught in pheromone traps adjacent to cotton fields did not develop as larvae on cotton.

In this study, we investigated the effect of host crop diversity and landscape composition on the abundance and natal host plant use of $H$. armigera in North Benin, West Africa. $H$. armigera is a polyphagous pest that causes yield losses to many crops worldwide, ${ }^{18}$ including cotton, ${ }^{1,19}$ cereals such as maize

\footnotetext{
* Correspondence to: N Tsafack, INP-ENSAT, Avenue de l'Agrobiopole, BP 32607 Auzeville, 31326 Castanet-Tolosan Cedex, France. E-mail: noelline.tsafackmenessong@ensat.fr

a INP-ENSAT, Auzeville, Castanet-Tolosan, France

b CIRAD, Dpt PERSYST, UPR 115 AIDA - AFRICARICE - 08 BP 841, Cotonou, Benin

c INRA UR 0980 SAD-Paysage, Rennes, France

d Monsanto LLC, St Louis, MO, USA

e INRA UMR 1201 DYNAFOR INRA, Castanet-Tolosan, France
} 
and sorghum, ${ }^{20,21}$ vegetable crops such as tomato, soybean and okra $^{22-25}$ and weeds such as Cleome viscosa. ${ }^{26,27}$ A study in West Africa reported that cotton was the preferred host plant of $H$. armigera. ${ }^{27}$ In Central Africa, $H$. armigera uses a succession of rainfed crops such as corn and cotton, as well as wild plants that offer a substantial resource limited in time to the growing season..$^{28}$ During the dry season, $H$. armigera populations persist as (i) locally diapausing individuals that are dispersed in local tomato-producing areas or (ii) individuals migrating over long distances to find suitable habitats. ${ }^{27}$ Thus, $H$. armigera is considered to be a facultative migrant species. Its local smaller-scale movements can give way to long migrations ${ }^{29}$ of up to $160 \mathrm{~km}^{30}$

In this study, we test the effect of host plant diversity on $\mathrm{H}$. armigera abundance and the relative contribution of alternative host plants to the infestation of cotton crops.

Firstly, considering the resource concentration hypothesis, ${ }^{31}$ we hypothesised that a high proportion of host plants (i.e. cotton, maize, tomato, sorghum) in a landscape should increase the immediate abundance of $\mathrm{H}$. armigera. We then considered the diversity of host crops as a measure of host plant temporal complementation favourable to $H$. armigera. We predicted that strong diversity of host crops in a landscape would be correlated with high abundance of $H$. armigera in cotton fields.

Secondly, considering natal host plant use (larval diet) of $H$. armigera adults, we hypothesised that the more host plants with a $\mathrm{C}_{3}$ (or $\mathrm{C}_{4}$ ) photosynthetic pathway there were in the landscape, the more $H$. armigera would be found to have $C_{3}$ (or $C_{4}$ ) natal origins. We therefore expected to find more $\mathrm{H}$. armigera positive to gossypol (having fed on cotton at the larval stage) in landscapes with a higher proportion of cotton.

\section{MATERIALS AND METHODS}

\subsection{Study site}

The study was carried out near the town of Angaradébou ( $11^{\circ}$ $29^{\prime}-3^{\circ} 20^{\prime} \mathrm{N}$ ) in northern Benin, West Africa (Fig. 1). Northern Benin is one of the most productive cotton areas in West Africa. ${ }^{32}$ It is also one of the most infested by $\mathrm{H}$. armigera, ${ }^{33,34}$ with damage reaching an average of nearly $50 \%$ of the cotton yield. ${ }^{32}$ The region is characterised by a tropical semi-arid and dry southern Sahel climate, consisting of a dry season lasting eight months (from October to mid-May) followed by a rainy season (from the end of May to early October). Most of the farms are made up of small fields of staple crops ( 0.8 ha on average for tomato, sorghum and maize) and larger cotton fields ( 2 ha on average) for cash. Crop rotations generally included cotton followed the year after by maize or sorghum. ${ }^{19}$ Weeding is generally manual (2-3 times for cotton). The majority of farmers used insecticides, and this was up to 10 times for cotton. Most cotton-producing farmers belong to a producers' cooperative that supervises chemical treatments for cotton crops. A previous study at the same study site has shown similar treatment frequencies for cotton among farmers. ${ }^{19}$ The resulting landscape is made up of approximately equal quarters of maize, cotton, natural vegetation and other crops (Tables 1 and 2; see $500 \mathrm{~m}$ buffer). Landscapes are also characterised by many scattered trees (principally shea trees, Vitellaria paradoxa) to produce shea oil and butter. During the dry season, vegetable crops are cultivated near wetlands close to the permanent Alibori River, the overall crop area declining by about $80 \%$ compared to the rainy season. The main host plants of $H$. armigera in the study area are cotton, tomato, maize and sorghum. ${ }^{19}$ Cotton is sown during the rainy season, between the end of May and the middle

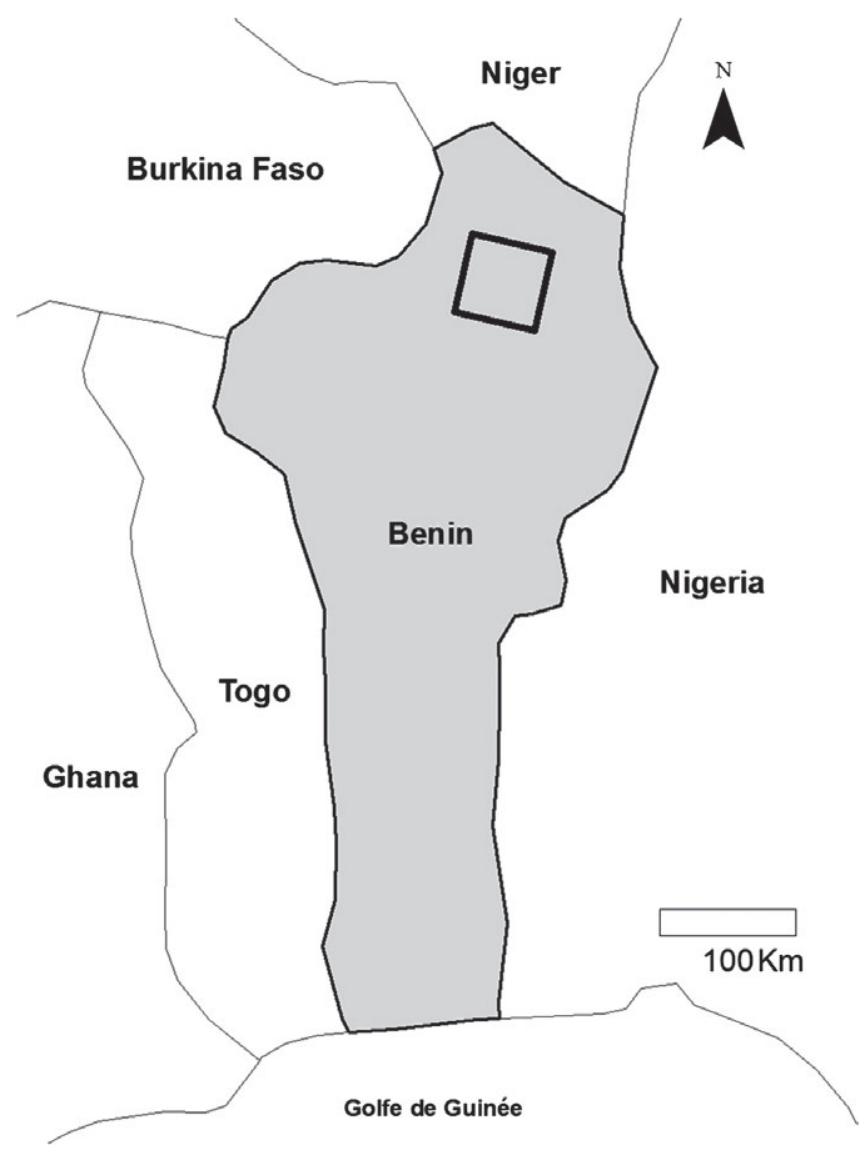

Figure 1. Location of the study area in northern Benin, with the black square bounding the entire study site.

of July, and harvested from November to December. Tomatoes are available all year round except during the driest months of the dry season (March to early May). Sorghum and maize are sown at the beginning of the rainy season (mid- to late May) and harvested at the end of September (Appendix A).

\subsection{Landscape selection and analysis}

We selected 37 cotton fields over two years (17 in 2011 and 20 in 2012). Owing to crop rotations, the fields were not the same for both years. The cotton fields were selected to be part of landscapes differing in their proportion of host crops (cotton, tomato, maize and sorghum) and semi-natural vegetation. Landcover was recorded in a $500 \mathrm{~m}$ radius buffer and integrated in a geographical information system using ArcGiS $10 .{ }^{35}$ In this study, the word 'buffer' denotes the agricultural landscape in a virtual circle around the trapping point. The choice of a $500 \mathrm{~m}$ radius was a trade-off between the mean cotton field size ( 1 ha, i.e. around $100 \mathrm{~m}$ per side) and our landcover-recording capacity in the field. To investigate how the local landscape influences the abundance of $H$. armigera and host plant use, we studied three nested buffer areas with a radius of 100,250 and $500 \mathrm{~m}$ centred on the trapping point (Fig. 2). The $500 \mathrm{~m}$ buffers in the study were distributed over an area of approximately $200 \mathrm{~km}^{2}$ in 2011 and $1000 \mathrm{~km}^{2}$ in 2012 . For each buffer radius, we extracted the proportion of cotton, tomato, maize, sorghum and natural vegetation and the $C_{3}$ and $C_{4}$ host crop proportions (Tables 1 and 2). Some crops, including millet, cowpea, rice and soybean, were present in very small proportion and thus categorised as 'other crops' (Table 1 and 2). The diversity 
Table 1. Landscape variables and their recorded ranges (in brackets) at the three nested spatial scales (100, 250 and $500 \mathrm{~m})$ in 2011

\begin{tabular}{|c|c|c|c|c|c|c|c|c|}
\hline \multirow[b]{2}{*}{ Variables } & \multirow[b]{2}{*}{ Unit } & \multirow[b]{2}{*}{ Description } & \multicolumn{2}{|c|}{ Buffer $100 \mathrm{~m}$} & \multicolumn{2}{|c|}{ Buffer $250 \mathrm{~m}$} & \multicolumn{2}{|c|}{ Buffer $500 \mathrm{~m}$} \\
\hline & & & mean & $\min -\max$ & mean & $\min -\max$ & mean & $\min -\max$ \\
\hline Co & $\%$ & Proportion of cotton & 68 & $27-100$ & 33 & $12-68$ & 26 & $4-58$ \\
\hline To & $\%$ & Proportion of tomato & 0 & 0 & 0 & 0 & 0 & 0 \\
\hline Ma & $\%$ & Proportion of maize & 15 & $0-59$ & 23 & $4-6$ & 22 & $11-52$ \\
\hline So & $\%$ & Proportion of sorghum & 1 & $0-7$ & 1 & $0-3$ & 1 & $0-3$ \\
\hline NV & $\%$ & Proportion of NV & 5 & $0-34$ & 17 & $3-50$ & 26 & $5-56$ \\
\hline Other & $\%$ & Proportion of other crops & 8 & $0-33$ & 21 & $0-54$ & 19 & $6-39$ \\
\hline$H$ & - & Shannon diversity index ${ }^{a}$ & 0.4 & $0.0-0.7$ & 0.6 & $0.4-0.7$ & 0.6 & $0.5-0.7$ \\
\hline$C_{3}$ & $\%$ & Proportion of $\mathrm{C}_{3} \mathrm{H}$. armigera host plants (cotton and tomato) & 68 & $27-99$ & 33 & $12-68$ & 26 & $4-58$ \\
\hline $\mathrm{C}_{4}$ & $\%$ & Proportion of $\mathrm{C}_{4} \mathrm{H}$. armigera host plants (maize and sorghum) & 16 & $0-59$ & 24 & $4-65$ & 23 & $11-53$ \\
\hline
\end{tabular}

a The Shannon diversity index $(H)^{36}$ is used to measure the host crop diversity: $H=\sum P_{i} \log P_{i}$, where $P_{i}$ is the proportion of a host crop type considered in the ith host plant category (cotton, tomato, maize, sorghum).

Table 2. Landscape variables and their recorded ranges (in brackets) at the three nested spatial scales (100, 250 and $500 \mathrm{~m})$ in 2012

\begin{tabular}{|c|c|c|c|c|c|c|c|c|}
\hline \multirow[b]{2}{*}{ Variables } & \multirow[b]{2}{*}{ Unit } & \multirow[b]{2}{*}{ Description } & \multicolumn{2}{|c|}{ Buffer 100 m } & \multicolumn{2}{|c|}{ Buffer 250 m } & \multicolumn{2}{|c|}{ Buffer 500 m } \\
\hline & & & mean & $\min -\max$ & mean & $\min -\max$ & mean & $\min -\max$ \\
\hline Co & $\%$ & Proportion of cotton & 55 & $11-100$ & 36 & $6-70$ & 25 & $5-55$ \\
\hline To & $\%$ & Proportion of tomato & 3 & $0-27$ & 2 & $0-9$ & 2 & $0-7$ \\
\hline $\mathrm{Ma}$ & $\%$ & Proportion of maize & 16 & $0-64$ & 25 & $1-58$ & 27 & $3-55$ \\
\hline So & $\%$ & Proportion of sorghum & 4 & $0-23$ & 8 & $0-22$ & 9 & $1-18$ \\
\hline NV & $\%$ & Proportion of NV & 12 & $0-45$ & 19 & $0-52$ & 28 & $5-55$ \\
\hline Other & $\%$ & Proportion of other crops & 3 & $0-22$ & 5 & $0-13$ & 9 & $1-18$ \\
\hline$H$ & - & Shannon diversity index & 0.5 & $0.1-1.2$ & 1.1 & $0.8-1.4$ & 0.8 & $0.6-1.1$ \\
\hline$C_{3}$ & $\%$ & Proportion of $\mathrm{C}_{3} \mathrm{H}$. armigera host plants (cotton and tomato) & 58 & $11-100$ & 37 & $6-70$ & 26 & $5-55$ \\
\hline $\mathrm{C}_{4}$ & $\%$ & Proportion of $\mathrm{C}_{4} \mathrm{H}$. armigera host plants (maize and sorghum) & 20 & $0-64$ & 32 & $6-59$ & 36 & $10-62$ \\
\hline
\end{tabular}

of $H$. armigera host crops in the landscape was calculated according to the Shannon diversity index ${ }^{36} \mathrm{H}$ :

$$
H=\sum P_{i} \log P_{i}
$$

where $P_{i}$ is the proportion of a host crop type considered in the ith host plant category (cotton, tomato, maize, sorghum) (Tables 1 and 2). The higher the value of $H$, the more diverse are the $H$. armigera host plants in the landscape.

\subsection{Abundance of Helicoverpa armigera by light trapping}

The abundance of $\mathrm{H}$. armigera was monitored using light traps (mercury vapour lamps of $160 \mathrm{~W}$ ), three poles and a white sheet $(180 \times 190 \mathrm{~cm})$, where insects, attracted by the light, landed. In the literature, light traps are presented as the best method for assessing moth abundance. ${ }^{37}$ We installed light traps from September to November (Appendices B and C), which corresponded to the peak of infestation in the study area. We installed light traps for $2 \mathrm{~h}$ before sunset ( 6.30 p.m. to 8.30 p.m.) at the centre of the selected cotton field. For fields where access to the centre was difficult without damaging crops, the trapping point was installed along the edges of the field. The landscape considered for the study was always the area centred to the GPS coordinate of the trapping point. The time period of the light trapping corresponds to the peak of $H$. armigera activity. ${ }^{38-40}$ With this trapping design, we mainly trapped the local population found in the cotton fields and their surroundings. To limit confounding effects, all light traps were placed away from shrubs and trees. In 2011, light traps were installed twice for each of the 17 fields. In 2012, light traps were installed 6 times for each of the 20 fields. Moths were then identified according to wing characters. The forewings have a series of dots on the margins, and there is a black comma-shaped marking in the middle underside of each forewing. The hind wings are lighter in colour, with a broad dark-brown border at the apical end; they have yellowish margins and strongly marked veins. ${ }^{41} \mathrm{All}$ individual $H$. armigera moths were preserved in alcohol (ethanol 95\%) for biochemical analyses.

\subsection{Determining the natal host plant use of Helicoverpa armigera}

2.4.1 Determining $C_{3}$ or $C_{4}$ natal host plant use by Helicoverpa armigera

Stable carbon isotopes can be used to identify the natal host plant. The method discriminates individuals that have fed on $\mathrm{C}_{3}$ plants from those that have fed on $C_{4}$ plants. ${ }^{17,42,43}$ Host plants with different photosynthetic pathways $\left(C_{3}\right.$ versus $C_{4}$ plants) leave an isotopic signature, specific to the plants on which the larvae have fed, in the adult insect's inert tissues (wings and chitin). ${ }^{16}$ The method involves analysing the ratio of carbon isotopes $(\delta \mathrm{C}) \mathrm{C} 12$ and $\mathrm{C} 13\left(\delta^{12} \mathrm{C} / \delta^{13} \mathrm{C}\right)$.

The $\delta^{13} \mathrm{C}$ of the wings were used as markers of the natal host plant, as they almost did not metabolise at the adult stage. ${ }^{15}$ Individuals were separated into two groups: (i) the $C_{3}$ group with a $\delta^{13} \mathrm{C}$ value of $-20 \%$ or less represents individuals that fed at the 


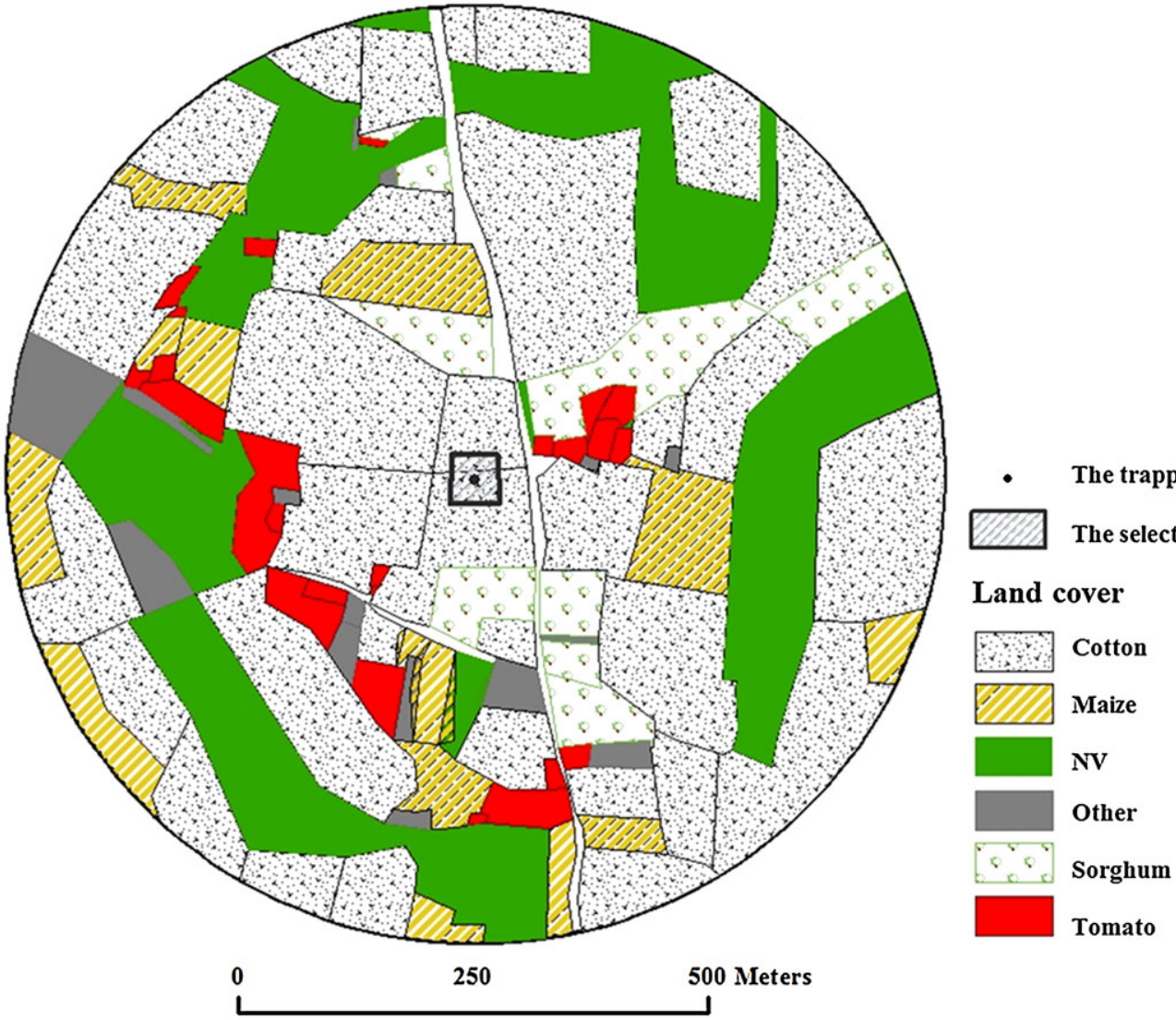

Figure 2. Schematic drawing of a $500 \mathrm{~m}$ buffer centred on a trapping point located at the centre of the selected cotton field. The buffer radiates out from the trapping point. NV: natural vegetation

larval stage on $C_{3}$ host plants (i.e. plants using the $C_{3}$ photosynthetic pathway, in this study mainly cotton and tomato); (ii) the $\mathrm{C}_{4}$ group with a $\delta^{13} \mathrm{C}$ value of $-15 \%$ or above represents individuals that fed on $\mathrm{C}_{4}$ host plants (i.e. plants using the $\mathrm{C}_{4}$ photosynthetic pathway, in this study mainly maize and sorghum). ${ }^{16,42-44}$

\subsubsection{Determining cotton use by Helicoverpa armigera through gossypol analysis}

To determine the use of cotton as a host plant, we analysed gossypol residues in moth extracts using a modified method (Appendix D) derived from the method presented in Head et al. ${ }^{17}$ Cotton has $\mathrm{a}_{3}$ photosynthetic pathway; thus, we analysed gossypol only in moths already identified as being in the $C_{3}$ group. A total of 1060 individual gossypol analyses were run (182 moths trapped in 2011 and 878 in 2012).

\subsection{Statistical analyses}

Because agricultural landscapes are not organised randomly, landscape analyses are often confronted with correlation between predictors. Spatial autocorrelation was checked using Moran's test ${ }^{45}$ in order to determine any spatial dependency between the values of the observed counting variables. The spatial weights that define the spatial structure of the observation sites were chosen to be the inverse of the distance between those sites. Moran's I-values range from -1 to +1 , where -1 is a negative autocorrelation (maximally unrelated) and +1 is a positive autocorrelation (maximally related). We ran a test for each year and for each counting variable.

We used the partial least-squares (PLS) approach to investigate the influence of the landscape context on (i) the abundance of $H$. armigera moths, (ii) the proportion of moths from the $\mathrm{C}_{3}$ and $\mathrm{C}_{4}$ groups and (iii) the proportion of moths that fed on cotton during their larval stage (the gossypol group), on all three spatial scales (buffer sizes of 100,250 and $500 \mathrm{~m}$ ). Thus, we built four models with the response variable corresponding firstly to the abundance of $H$. armigera moths, secondly to the proportion of moths from the $\mathrm{C}_{3}$ group, calculated as $\mathrm{C}_{3} /\left(\mathrm{C}_{3}+\mathrm{C}_{4}\right)$, thirdly to the proportion of moths from the $\mathrm{C}_{4}$ group and fourthly to the proportion of moths that fed on cotton during their larval stage. For abundance and gossypol group models, the predictors included the proportions of cotton, tomato, maize, sorghum, natural vegetation and other crops and the diversity of host crops. The diversity of host crops, the proportions of natural vegetation and of other crops and the proportion of $C_{3}$ host plants or $C_{4}$ host plants were used to predict the proportion of moths from the $C_{3}$ or $C_{4}$ groups. Each predictor was considered separately for each year (e.g. for cotton proportion, the proportion in 2011 and the proportion in 2012 are two predictors in a model).

We chose the PLS approach because PLS is particularly well suited to the analysis of a large array of related (i.e. not truly independent) predictor variables with a small sample compared with the number of predictors. ${ }^{46}$

Because our response variables fitted Poisson (count) and binomial (proportion) distributions rather than a normal distribution, we used a GLM-PLS using the link function of the generalised linear model (log for count and logit for proportions). ${ }^{47}$ Owing to the large number of explanatory variables, only 2 years of survey data and the fact that we have few ecological hypotheses to suspect 
(a)

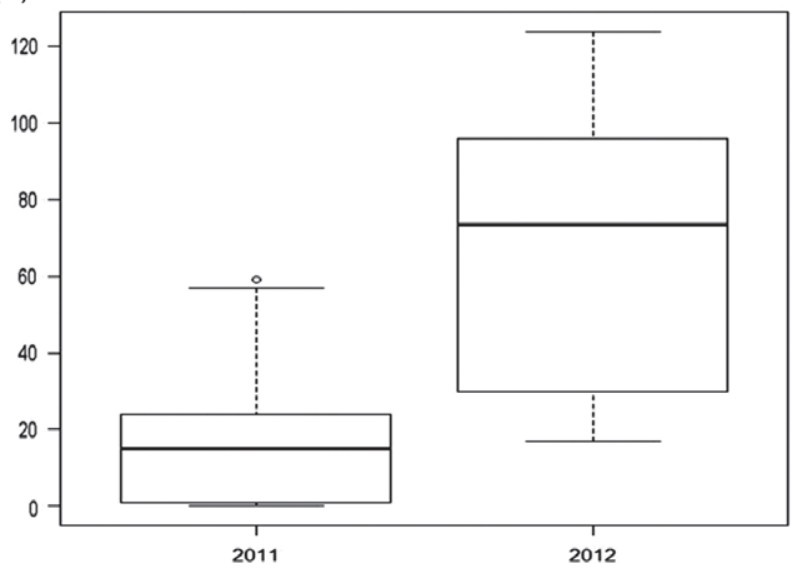

(c)

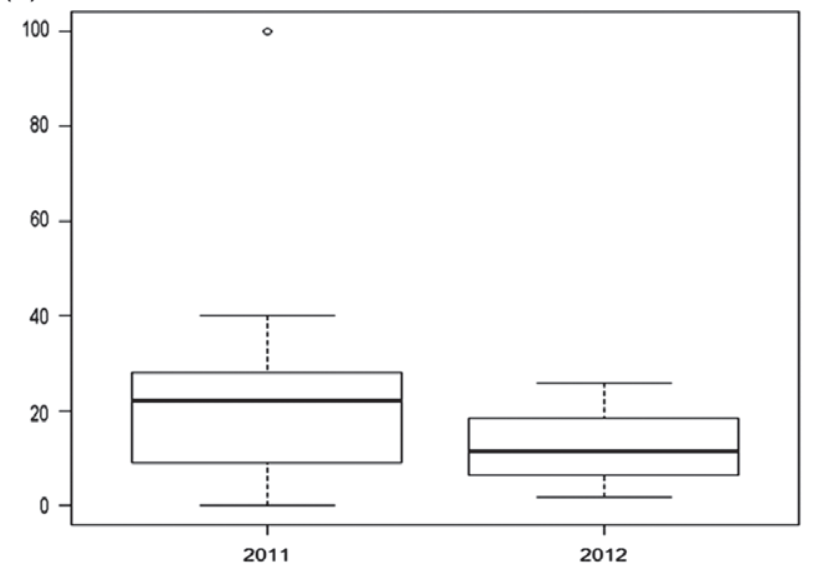

(b)

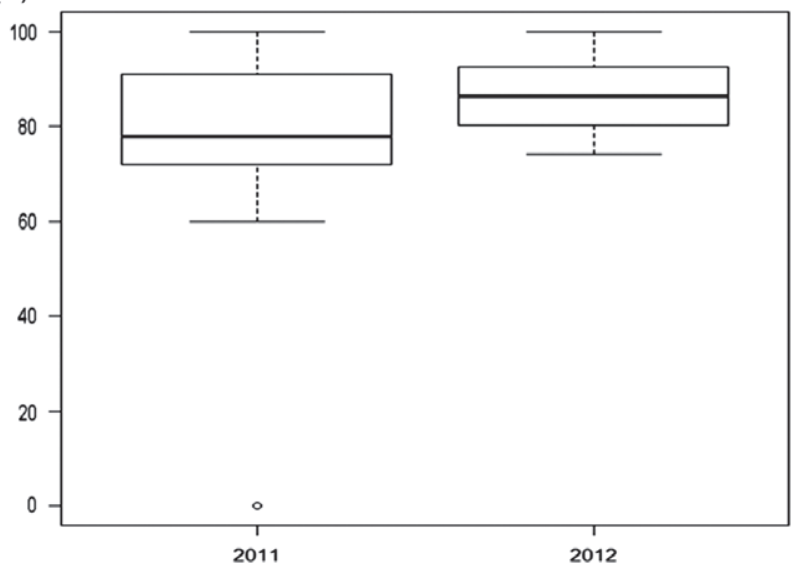

(d)

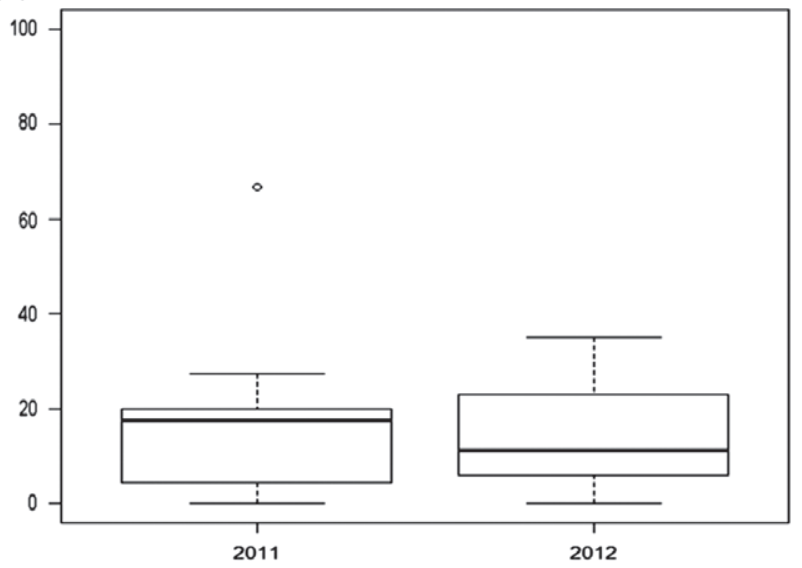

Figure 3. Distribution per site of $(A)$ the number of Helicoverpa armigera moths trapped, $(B)$ the proportion of $C_{3}$ moths analysed relative to all analysed moths, $(C)$ the proportion of $C_{4}$ moths analysed relative to all analysed moths and (D) the proportion of moths positive to gossypol relative to the number of $C_{3}$ moths, in 2011 and 2012. The box represents the interquartile range (IQR), containing 50\% of the values. The line across the box represents the median value, and the ends of the whiskers represent the lowest datum still within 1.5 IQR of the lower quartile and the highest datum still within 1.5 IQR of the upper quartile. Outliers are represented as small circles.

interactions between variables, we focused on the independent effect of each variable, excluding interaction.

We also computed VIP (Variable Importance in Projection) values for each predictor variable. VIP values quantify the ability of each predictor variable to explain the variation in the response variable. In our study, we chose for VIP value a threshold at 1 (VIP $\geq 1$ ), which seemed the most discriminating. ${ }^{48}$ Thus, variables with $\mathrm{VIP} \geq 1$ were considered to be significant for predicting the response variable. ${ }^{48}$ Coefficient estimates of predictors were extracted to quantify and identify the sign of the predictor effect.

All statistical analyses were carried out using the free statistical software ${ }^{49}$ R 2.15 .2 with the plsRglm package ${ }^{45}$ for PLS on GLM. We modified the function of the package because, as it stands, it accepts only the classical $0-1$ values in the case of the binomial family. From gossypol analyses, we had a number of positives and a number of negatives that did not fall in the classical 0-1 binomial family. We also added some code to compute VIP values for the GLM-PLS procedure.

\section{RESULTS}

Overall, 277 H. armigera moths in 2011 and 1352 in 2012 were trapped. Because there were more $H$. armigera trapped per trapping point in 2012 than in 2011 (Fig. 3A) owing to a variation in the frequency of light trapping (twice in 2011 for each of the 17 trapping points and six for each of the 20 trapping points in 2012), the overall results are presented for each year separately in the graphs and tables. No spatial autocorrelation was detected: all computed values of Moran's I were neither close to -1 nor close to +1 . They ranged from -0.43 to +0.37 .

\subsection{Abundance of Helicoverpa armigera}

The whole GLM-PLS model explained $65 \%$ of the variance in the abundance of moths (Table 3). According to VIP, the influence of landscape variables on the abundance of $H$. armigera varied according to the spatial scales and the year (Table 4).

For both years, the diversity in host crops $(H)$ was a significant variable (VIP $>1)$, mostly with a positive effect on $H$. armigera abundance, except in 2012 for the $100 \mathrm{~m}$ and $250 \mathrm{~m}$ buffers (Table 4). The proportion of cotton crop was significantly related to $H$. armigera abundance only in 2012, positively on $100 \mathrm{~m}$ and negatively on $250 \mathrm{~m}$ buffer scales (Table 4). In 2011, for the $500 \mathrm{~m}$ buffer size, the proportion of sorghum was positively related to H. armigera abundance (Fig. 4 and Table 4). In 2012, between the major host crops (cotton, maize, sorghum and tomato), two were relevant on the $500 \mathrm{~m}$ scale to explain $H$. armigera abundance: the proportions of tomato and sorghum (Fig. 4). In the same year, 
Table 3. Akaike information criterion (AIC), null deviance, residual deviance and $R^{2}(\%)$ for each of the four GLM-PLS models performed. Responses and explanatory variables of each model are presented (see code in Table 1)

\begin{tabular}{|c|c|c|c|c|}
\hline Predictive models & Abundance & $C_{3}$ group & $\mathrm{C}_{4}$ group & Gossypol \\
\hline Response variable & $\begin{array}{c}\text { Total number of moths } \\
\text { trapped }\end{array}$ & $\begin{array}{l}\text { Total number of individuals } \\
\text { with } \mathrm{a}_{3} \text { signature }\end{array}$ & $\begin{array}{l}\text { Total number of individuals } \\
\text { with a } C_{4} \text { signature }\end{array}$ & $\begin{array}{l}\text { Total number of } C_{3} \\
\text { individuals that were } \\
\text { positive to gossypol }\end{array}$ \\
\hline Explanatory variables & $\begin{array}{c}\text { Co, To, Ma, So, NV, other } \\
\text { and } H\end{array}$ & $\mathrm{C}_{3}$ host plants, NV, other and & $\mathrm{C}_{4}$ host plants, NV, other and & Co, To, Ma, So, NV, other and \\
\hline AIC & 489.9 & 137.1 & 136.8 & 128.8 \\
\hline Null deviance & 1360 & 82.61 & 82.61 & 106 \\
\hline Residual deviance & 301.1 & 31.45 & 31.14 & 29.03 \\
\hline$R^{2}(\%)$ & 64.53 & 61.93 & 64.86 & 72.61 \\
\hline
\end{tabular}

Table 4. GLM-PLS coefficient estimates of landscape variables to explain the abundance of Helicoverpa armigera (refer to Table 1 for the complete name of variables). In bold, coefficient estimates of significant variables (with VIP $\geq 1$ ). A dash indicates the absence of tomato proportion in the 2011 dataset, so the variable was not integrated in the model for this year

\begin{tabular}{|lcc|} 
Landscape variables & 2011 & 2012 \\
\hline Co100 & +0.0033 & $+\mathbf{0 . 0 0 1 5}$ \\
Co250 & +0.0026 & $-\mathbf{0 . 0 0 2 0}$ \\
Co500 & -0.0003 & -0.0019 \\
To100 & - & +0.0031 \\
To250 & - & +0.00464 \\
To500 & - & $+\mathbf{0 . 0 8 8 6}$ \\
Ma100 & -0.0078 & +0.0021 \\
Ma250 & -0.0037 & +0.0073 \\
Ma500 & -0.0048 & +0.0040 \\
So100 & +0.0110 & +0.0059 \\
So250 & -0.0034 & $-\mathbf{0 . 0 0 7 0}$ \\
So500 & $+\mathbf{0 . 0 0 8 5}$ & $+\mathbf{0 . 0 1 6 7}$ \\
NV100 & +0.0042 & +0.0057 \\
NV250 & -0.0067 & -0.0013 \\
NV500 & +0.0014 & $-\mathbf{0 . 0 0 4 2}$ \\
Other100 & -0.0409 & +0.0096 \\
Other250 & -0.0076 & +0.0153 \\
Other500 & -0.0085 & $+\mathbf{0 . 0 0 0 2}$ \\
H100 & +0.4984 & $-\mathbf{0 . 2 2 4 2}$ \\
H250 & $+\mathbf{0 . 3 4 1 8}$ & $\mathbf{- 1 . 5 7 0 7}$ \\
H500 & $+\mathbf{0 . 8 5 9 4}$ & $+\mathbf{0 . 3 6 3 8}$ \\
\hline
\end{tabular}

the proportions of natural vegetation and other crops were also significant related to the abundance of $H$. armigera: a negative relationship to the proportion of natural vegetation and a positive relationship to the proportion of other crops (Fig. 4 and Table 4).

\section{2 $C_{3}$ and $C_{4}$ host plant use by Helicoverpa armigera}

Of the 277 individuals trapped in 2011, 240 moths were in appropriate condition to analyse carbon isotopes in order to determine the natal host plant photosynthetic pathways. We found that $76 \%$ (182 moths) had a $C_{3}$ natal host plant and 24\% (58 moths) had a $\mathrm{C}_{4}$ natal host plant. Of the 1352 individuals trapped in 2012, we analysed 1009 moths and found that $87 \%$ (878 moths) were from $C_{3}$ natal host plants, and $13 \%$ (111 moths) from $C_{4}$ plants. Twenty individuals could not be assigned to one group or the other, so they were not used in the subsequent analyses (Appendix E).

GLM-PLS explained 62 and $65 \%$ of the variance (Table 3 ) for the $\mathrm{C}_{3}$ and $\mathrm{C}_{4}$ groups respectively.

Two variables were important in the projection (VIP $>1)$ for the model considering the abundance of the $C_{3}$ group: the diversity of host crops $(H)$ for both years, except at the $100 \mathrm{~m}$ scale in 2011, and the proportion of $C_{3}$ host crops only in 2012 (Table 5). In 2011 and 2012 , the diversity of host crops had mostly a negative relationship to the abundance of moths from the $C_{3}$ group, except in 2012 at $100 \mathrm{~m}$, where the relationship was positive (Table 5). Thus, at the $500 \mathrm{~m}$ scale, $H$ was for both years significantly and negatively related to the abundance of $H$. armigera from the $C_{3}$ group (Fig. 5A). The relationship between the abundance of moths from the $C_{3}$ group and the proportion of $\mathrm{C}_{3}$ host crops was significant and positive only in 2012 (Table 5).

Two variables were important in the projection $(\mathrm{VIP}>1)$ for the model considering the abundance of the $C_{4}$ group (Table 6). The $C_{4}$ group abundance was positively related to $H$ in the $250 \mathrm{~m}$ buffer in 2011 and 2012 and in the 100 m buffer in 2012 only. However, host crop diversity in the $500 \mathrm{~m}$ buffer had a negative effect in 2011 and 2012 (Fig. 5B). The relationship between the abundance of $C_{4}$ group moths and the proportion of $\mathrm{C}_{4}$ host plants was positive when considered in a $250 \mathrm{~m}$ buffer but negative at $500 \mathrm{~m}$ for both years (Table 6).

The proportion of natural vegetation and other crops was never significant when seeking to explain $C_{3}$ or $C_{4}$ group abundance $(\mathrm{VIP}<1)$, in either year of the study (Tables 5 and 6 ).

\subsection{Cotton use by Helicoverpa armigera}

Of the moths in the $\mathrm{C}_{3}$ group, $20 \%$ ( $N=36$ moths) were found to be positive to gossypol in 2011 and 13\% ( $N=113$ moths) in 2012 (Fig. 3). GLM-PLS explained $73 \%$ of the variation (Table 3 ).

The proportion of individuals that fed on cotton plants had little relationship to the proportion of cotton crops in the landscape. The proportion of cotton had a VIP value over 1 only once in 2011 with the $500 \mathrm{~m}$ buffer (Fig. 6). The diversity of host crops $(H)$ had a significant VIP value for both years and at all three scales (Fig. 6 and Table 7). Its influence was negative in 2011 for both the $100 \mathrm{~m}$ and $500 \mathrm{~m}$ buffers and positive for the $250 \mathrm{~m}$ buffer. On the other hand, its influence was positive in 2012 for both the $100 \mathrm{~m}$ and $250 \mathrm{~m}$ buffers and negative for the $500 \mathrm{~m}$ buffer (Fig. 6 and Table 7). The proportion of individuals positive for gossypol was significantly and negatively correlated with the proportion of sorghum in the landscape in 2011 and 2012 in both the $100 \mathrm{~m}$ and $500 \mathrm{~m}$ buffers (Fig. 6 and Table 7). In 2012, the proportion of tomato was negatively correlated with the abundance of moths 


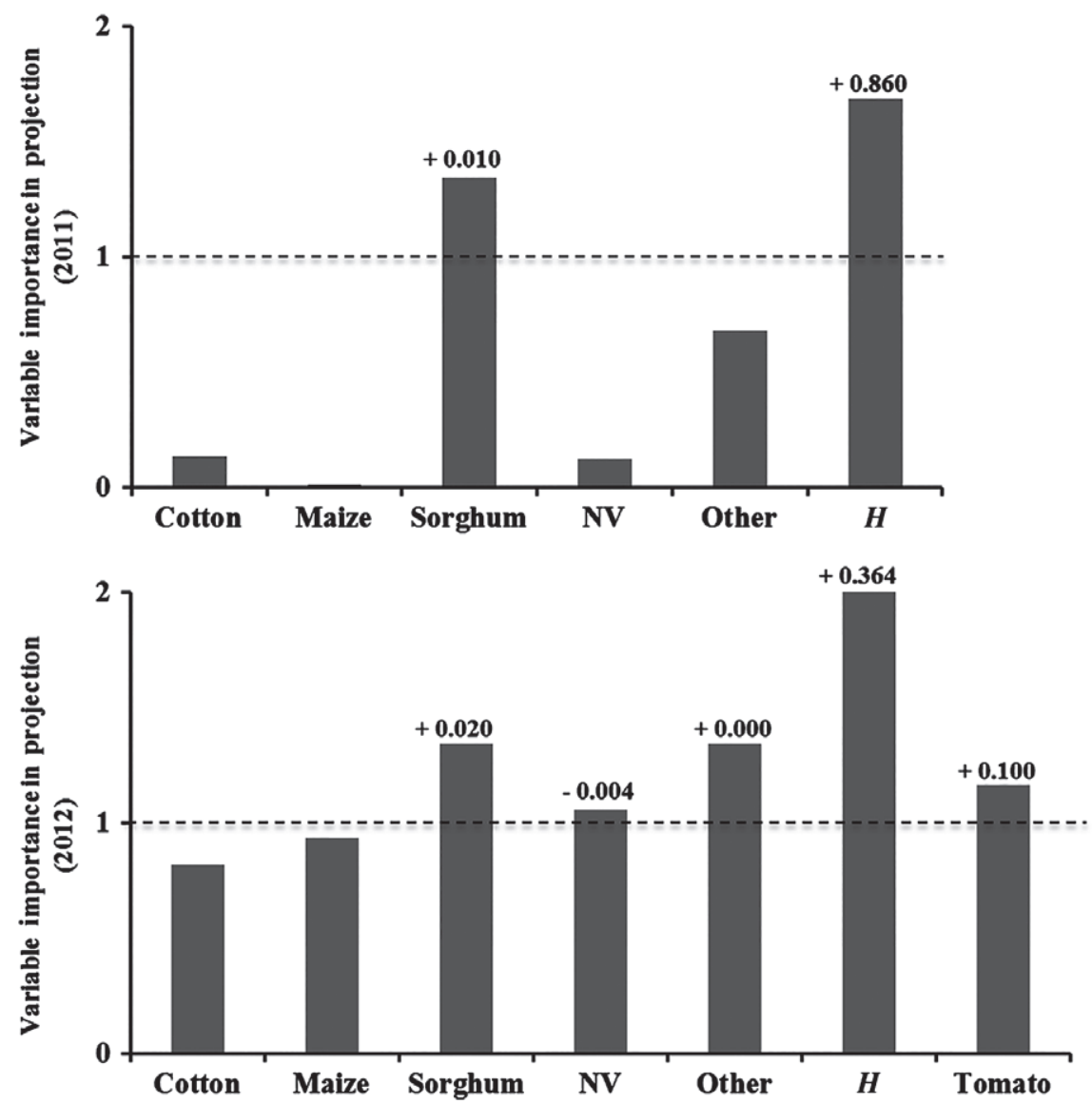

Figure 4. Variable importance in projection of the landscape variables investigated to predict the abundance of Helicoverpa armigera at the $500 \mathrm{~m}$ buffer. VIP values were extracted from GLM-PLS performed at the three nested spatial scales (100, 250 and $500 \mathrm{~m}$ buffers) for the two years (2011 and 2012 ). VIP values are represented by the size of the bars. Bars crossed by the dotted line are significant (VIP $\geq 1)$ predictors of the abundance of $H$. armigera. Coefficient estimates of significant predictors are presented above the bars. Refer to Table 1 for the complete name of variables. The explanatory variable 'tomato' is missing in 2011 because we did not find tomato plants in the landscape surrounding the trapping points.

Table 5. GLM-PLS coefficient estimates of landscape variables used to explain the proportion of Helicoverpa armigera having fed on $\mathrm{C}_{3}$ host plants at the larval stage (refer to Table 1 for the complete name of variables). In bold, coefficient estimates of significant variables (with VIP $\geq 1)$

\begin{tabular}{llc|} 
Landscape variables & 2011 & 2012 \\
\hline C $_{3}$ host plants100 & +0.0050 & $\mathbf{+ 0 . 0 0 9 5}$ \\
C $_{3}$ host plants250 & -0.0104 & $+\mathbf{0 . 0 0 0 5}$ \\
C3 host plants500 & -0.0095 & $+\mathbf{0 . 0 0 7 3}$ \\
NV100 & -0.0103 & -0.0067 \\
NV250 & -0.0044 & -0.0124 \\
NV500 & +0.0080 & +0.0095 \\
Other100 & -0.0149 & +0.0177 \\
Other250 & +0.0003 & +0.0263 \\
Other500 & +0.0008 & -0.0227 \\
H100 & +0.6551 & $+\mathbf{0 . 4 5 9 4}$ \\
H250 & $-\mathbf{0 . 4 4 7 1}$ & $-\mathbf{0 . 4 3 5 9}$ \\
H500 & $-\mathbf{0 . 0 8 8 4}$ & $\mathbf{0 . 1 3 5 0}$ \\
\hline
\end{tabular}

with gossypol signature for the $250 \mathrm{~m}$ and $500 \mathrm{~m}$ buffers (Fig. 6 and Table 7). The proportion of natural vegetation was significant and positive for the $500 \mathrm{~m}$ buffer in 2012 (Fig. 6 and Table 7).
Table 6. GLM-PLS coefficient estimates of landscape variables used to explain the proportion of Helicoverpa armigera having fed on $C_{4}$ host plants at the larval stage (refer to Table 1 for the complete name of variables). In bold, coefficients of significant variables (with VIP $\geq 1$ )

\begin{tabular}{|llc|} 
Landscape variables & 2011 & 2012 \\
\hline C $_{4}$ host plants100 & +0.0031 & +0.0079 \\
C $_{4}$ host plants250 & $\mathbf{- 0 . 0 1 9 2}$ & $-\mathbf{0 . 0 1 3 1}$ \\
C $_{4}$ host plants500 & $+\mathbf{0 . 0 0 2 3}$ & $+\mathbf{0 . 0 0 7 4}$ \\
NV100 & +0.0121 & +0.0115 \\
NV250 & -0.0001 & +0.0114 \\
NV500 & -0.0151 & -0.0148 \\
Other100 & +0.0034 & -0.0221 \\
Other250 & -0.0068 & -0.0262 \\
Other500 & -0.0059 & +0.0351 \\
H100 & -0.2759 & $+\mathbf{0 . 3 4 3 9}$ \\
H250 & $+\mathbf{0 . 8 3 9 6}$ & $+\mathbf{0 . 0 3 9 5}$ \\
H500 & $-\mathbf{0 . 1 5 6 5}$ & $\mathbf{- 0 . 9 0 2 3}$ \\
\hline
\end{tabular}

\section{DISCUSSION}

Our study investigated the influence of host crop proportion and diversity on $\mathrm{H}$. armigera abundance and larval host plant use on three spatial scales $(100,200$ and $500 \mathrm{~m})$. We found that host crop diversity was mostly positively related to the abundance of 
(a)
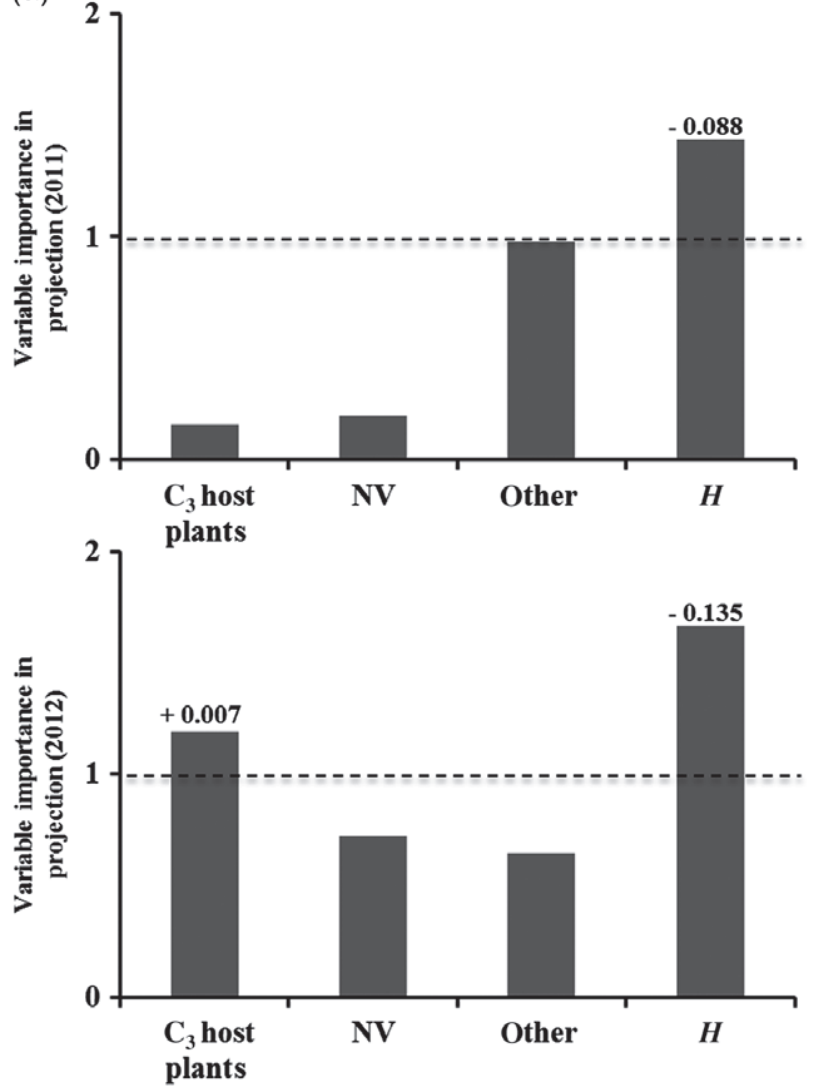

(b)
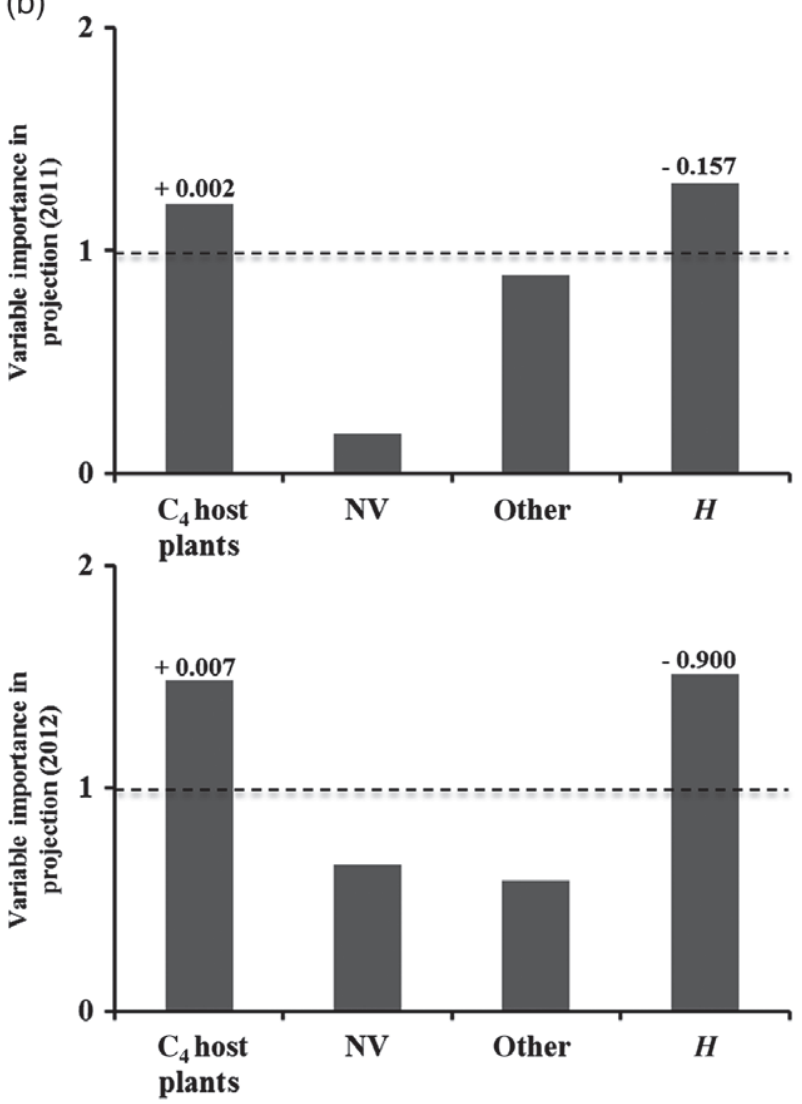

Figure 5. Variable importance in projection of the landscape variables investigated to predict the proportion of Helicoverpa armigera with $(A) C_{3}$ natal host plants and (B) $C_{4}$ natal host plants at the $500 \mathrm{~m}$ buffer for the two years (2011 and 2012). Bars crossed by the dotted line are significant (VIP $\geq 1$ ) predictors of the proportion of $\mathrm{H}$. armigera of $C_{3}$ group $(A)$ and $C_{4}$ group (B). Coefficient estimates of significant predictors are presented above the bars. Refer to Table 1 for the complete name of variables.

H. armigera adults for a particular location in each landscape. The proportion of adults having fed on $\mathrm{C}_{3}$ host plants was positively related to the proportion of $C_{3}$ host plants in the landscape, but the role of host crop diversity was mostly negative. The proportion of moths whose larvae had fed on cotton was low and was weakly related to the proportion of cotton in the landscape.

\subsection{The $500 \mathrm{~m}$ buffer was the best scale to investigate the role of landscape elements in the abundance and natal host use of Helicoverpa armigera}

The scale of effect is the spatial extent to which landscape structure best predicts population response. ${ }^{50}$ To analyse the scale of effect for $\mathrm{H}$. armigera, we chose the widely used method of nested buffers of increasing size. Firstly, we showed a general trend towards an increasing number of significant explanatory variables as the buffer zone increased $(500 \mathrm{~m})$. We thus conclude that, of the three spatial scales considered, the 500 m extent appears to be the most meaningful in explaining $H$. armigera abundance; an even larger scale might have provided more explanatory power, but we did not have the capacity to undertake work beyond this scale. The scale of effect is linked to the dispersal abilities of the studied species. ${ }^{50,51}$ The mutivoltine and highly mobile characteristics of $H$. armigera make pest management at both individual crop and farm scales problematic. ${ }^{52}$ Our results suggest that it is essential to consider the landscape context in a buffer zone with a radius of at least $500 \mathrm{~m}$ in order to manage H. armigera outbreaks. However, some explanatory variables did not show consistent coefficient signs depending on the buffer size. In this study, if a variable showed mainly positive coefficients except for one buffer size, we considered that the variable had a general positive trend. Sometimes this divergence could be explained, like the change in sign of the influence of host crop diversity on the proportion of adults having fed on $\mathrm{C}_{3}$ host plants. Host crop diversity may have little ecological meaning when considered at the smallest scale $(100 \mathrm{~m})$ surrounded by large fields (which thus reduce the diversity). At the same time, diversity of host crop had a significant, negative effect on the proportion of adults having fed on $\mathrm{C}_{3}$ host plants for the $250 \mathrm{~m}$ and $500 \mathrm{~m}$ buffers for both years. However, we did not find any reason for the proportion of adults having fed on $C_{4}$ plants to be linked alternatively positively or negatively to the proportion of $\mathrm{C}_{4}$ host plant and diversity of host crops in the $250 \mathrm{~m}$ and $500 \mathrm{~m}$ buffers. An unexplained change in signs depending on the spatial extent of analyses has been reported in other studies. ${ }^{53,54}$ The results of these studies do not address the scale of effect of a species but the ambivalent role of certain landscape elements. The same authors advocate the careful use of landscape variables when they do not have convergent relationships with the focal species.

\subsection{Host crop diversity was the main landscape effect on the abundance of Helicoverpa armigera}

We showed that, at the largest scale measured, host crop diversity influenced positively the abundance of $H$. armigera. This result is consistent with those of two meta-analyses concluding that pest 


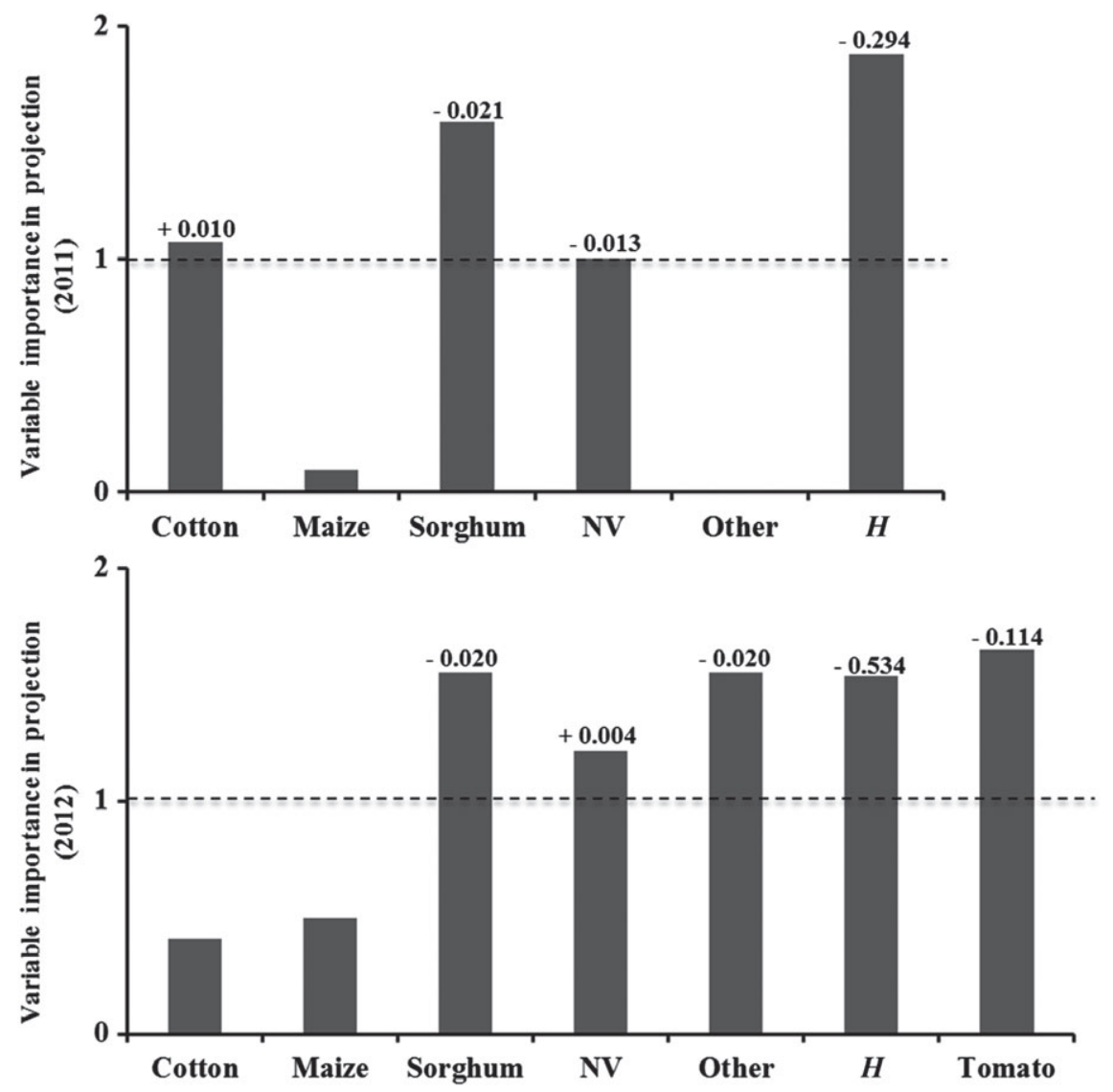

Figure 6. Variable importance in projection of the landscape variables investigated to predict the proportion Helicoverpa armigera that fed on cotton during their larval stage (gossypol signature) at the $500 \mathrm{~m}$ buffer for the two years (2011 and 2012). Bars crossed by the dotted line are significant (VIP $\geq 1$ ) predictors of the proportion of $H$. armigera that fed on cotton during their larval stage. Coefficient estimates of significant predictors are presented above the bars. Refer to Table 1 for the complete name of variables. The explanatory variable 'tomato' is missing in 2011 because we did not find tomato plants in the landscape surrounding the trapping points.

abundance was positively correlated with crop diversity. ${ }^{54,55}$ In the same way, a greater diversity of host plants in the landscape enhanced the abundance in cotton fields of Lygus hesperus, a polyphagous pest. ${ }^{56}$ Owing to its polyphagy, H. armigera is attracted by different host plants, and its life cycle depends on the suitability of the host plant at a given time. Host plant diversity provides a range of refuges and alternative resources that enhance polyphagous species. In our study area, the importance of a higher diversity of host crops in increased $H$. armigera numbers could be due to the presence of host crops such as tomato and sorghum, found in low proportions in the landscape. Indeed, when sorghum and tomato were positively related to $H$. armigera abundance, host crop diversity was also positively related to $H$. armigera abundance. However, tomato was never more than $5 \%$ on average of the agricultural landscape, and sorghum averaged 10\%; even allowing for their attractiveness as hosts, this influence on $H$. armigera abundance must be considered with caution. ${ }^{18}$

\subsection{The effect of landscape on natal host plant use}

4.3.1 The abundance of moths having developed on $C_{3}$ and $C_{4}$ host plants was related to $C_{3}$ and $C_{4}$ plants in the landscape

We found that the more $C_{3}$ host plants there were in the landscape, the more $H$. armigera had fed on $\mathrm{C}_{3}$ host plants, but this relationship was significant only in 2012, when the total number of moths trapped per trapping point was higher. This result was not due to a cotton effect because the proportion of cotton crops in the landscape did not explain the proportion of individuals positive to gossypol (i.e. having fed on cotton plants at the larval stage). Individuals having fed on $C_{3}$ plants may have developed on tomato plants, which are the other $C_{3}$ plants in the landscape. Knowing that tomato proportion was never more than $5 \%$ on average in landscapes, and was present only in 2012, the hypothesis should be verified by further studies. Another hypothesis is that moths having fed on $\mathrm{C}_{3}$ plants may have used other uncultivated $C_{3}$ host plants considered to be natural vegetation (such as Cleome viscosa ${ }^{26,27,42}$ which is a $C_{3}$ wild plant present at the study sites), but we found no significant relationship to the proportion of natural vegetation.

4.3.2 No relationships between the abundance of moths developed on cotton crops and the proportion of cotton in the landscape

The absence of relationships between the proportion of individuals positive to gossypol (i.e. having fed on cotton plants at the larval stage) and the proportion of cotton in the landscape could be explained by individuals coming from cotton fields over $500 \mathrm{~m}$ away. These results are based on 36 individuals in 2011 and 113 individuals in 2012 that were positive to gossypol. Moreover, some individuals having fed on cotton may not have had a strong enough signature to be declared positive. There is currently a rapid development of analytical methods to identify the natal origins of 'heterometabolic' insects; for example, resistance to insecticides 
Table 7. GLM-PLS coefficient estimates of landscape variables used to explain the proportion of Helicoverpa armigera that fed on cotton during their larval stage (gossypol signature) (refer to Table 1 for the complete name of variables). In bold, coefficient estimates of significant variables (with VIP $\geq 1$ ). A dash indicates the absence of tomato proportion in the 2011 dataset, so the variable was not integrated in the model for this year

\begin{tabular}{|lcc|} 
Landscape variables & 2011 & 2012 \\
\hline Co100 & -0.0038 & -0.0024 \\
Co250 & -0.0027 & -0.0053 \\
Co500 & $+\mathbf{0 . 0 0 7 5}$ & +0.0015 \\
To100 & - & -0.0230 \\
To250 & - & $-\mathbf{0 . 0 2 2 4}$ \\
To500 & - & $-\mathbf{0 . 1 1 4 3}$ \\
Ma100 & +0.0043 & +0.0047 \\
Ma250 & +0.0008 & +0.0004 \\
Ma500 & +0.0030 & +0.0012 \\
So100 & $-\mathbf{0 . 0 1 2 8}$ & $-\mathbf{0 . 0 1 0 3}$ \\
So250 & +0.0166 & +0.0190 \\
So500 & $-\mathbf{0 . 0 2 0 8}$ & $-\mathbf{0 . 0 1 8 8}$ \\
NV100 & -0.0032 & -0.0079 \\
NV250 & +0.0024 & +0.0013 \\
NV500 & $-\mathbf{0 . 0 1 2 9}$ & $+\mathbf{0 . 0 0 4 3}$ \\
Other100 & $+\mathbf{0 . 0 0 6 3}$ & $+\mathbf{0 . 0 3 8 2}$ \\
Other250 & -0.0035 & +0.0251 \\
Other500 & $\mathbf{0 . 0 1 8 8}$ \\
H100 & $\mathbf{+ 0 . 5 2 2 1}$ & $+\mathbf{0 . 1 2 7 6}$ \\
H250 & $+\mathbf{1 . 1 8 1 7}$ & $+\mathbf{1 . 1 6 1 3}$ \\
H500 & $\mathbf{- 2 . 9 3 9 0}$ & $\mathbf{0 . 5 3 4 3}$ \\
\hline & & \\
\hline
\end{tabular}

might be a powerful method for detecting individuals having fed on tomato crops. ${ }^{28}$

Our study demonstrated that cotton was a minor contributor to the natal origin of the captured moths. Our result is consistent with those of Kyi et al., ${ }^{57}$ who found that egg survival in cotton crops was poor in an experimental study. This finding is counterintuitive, however, as we had hypothesised that individuals present during the infestation peak (mid-September to end of October) on cotton had already spent at least one generation on cotton. In addition, previous studies showed that cotton fields were more infested by $\mathrm{H}$. armigera than other crops, but that cotton was not the primary host selected for oviposition or feeding. ${ }^{27,30}$ The absence of effect of cotton proportion on moth abundance may also be explained by insect learning. Learning for host selection has been demonstrated ${ }^{58}$ in many insect species. Indeed, the experience of $H$. armigera adults can significantly affect the relative acceptability of host plants for ovipositing or feeding. ${ }^{59}$ In this way, learning may alter $\mathrm{H}$. armigera host plant preference for cotton and mask the effect of cotton proportion in the landscape on the abundance of moths. Another hypothesis to explain our results concerns environmental cues for diapause, a strategy by which insects avoid unfavourable conditions. ${ }^{60}$ In a study investigating diapause induction on $\mathrm{H}$. armigera, it was demonstrated that larval host plants may influence the occurrence of a long diapause. In particular, the authors showed that cotton plants induced diapause 2-5 times more than tomato and maize respectively. ${ }^{61}$

Considering the source/sink concept, cotton in the landscape may act as a net sink for $H$. armigera, as our previous studies ${ }^{19}$ in the same region show high infestation of cotton fields by $H$. armigera larvae. However, many studies investigating this concept found changes in the source/sink effects ${ }^{62,63}$ of a given landscape element through the season and with the landscape scale. ${ }^{63}$ In our study, we investigated the effect of landscape context on the immediate abundance of $H$. armigera and not the dynamics of the population.

\subsection{Importance of tomato crops for Helicoverpa armigera}

Unlike the proportion of cotton in the landscape, the proportion of tomato crops was important in explaining the abundance of $H$. armigera in the landscape. However, the importance of tomato proportion should be treated with some caution because it is very heavily sprayed ${ }^{19}$ and was not present in our study area in 2011. We found a positive relationship to the abundance of $H$. armigera for the $500 \mathrm{~m}$ buffer. This finding is in accordance with the argument that, by providing earlier flowering opportunities, tomato plants may host $H$. armigera more than cotton does, and thus support the abundance of $\mathrm{H}$. armigera in the landscape. ${ }^{13}$ The relative importance of the proportion of tomato plants was also demonstrated for larval abundance in the landscape. ${ }^{19}$. The proportion of tomato plants in the landscape may explain a significant proportion of individuals having fed on $C_{3}$ plants, because tomato plants, like cotton, have a $C_{3}$ photosynthetic pathway ${ }^{64}$ Further studies should focus on tomato plants as larval host plants with the development of a marker, but the biochemical tomato marker tomatine has been difficult to implement. ${ }^{65}$ Resistance to insecticides used for tomato crops should also be investigated. ${ }^{42}$

\section{CONCLUSION}

To our knowledge, this is the first study to use natal host plant origin to determine the influence of landscape diversity and composition on $\mathrm{H}$. armigera infestations. Our results suggest that it is essential to consider the landscape context in a buffer zone with a radius of at least $500 \mathrm{~m}$ in order to manage $H$. armigera outbreaks even for small-scale agricultural systems. We found that host plant diversity at a scale of $500 \mathrm{~m}$ buffer (78.5 ha) is the best predictor of abundance of $H$. armigera moths. The landscape variables influencing $H$. armigera abundance are not always convergent with those involved in larvae abundance leading to crop damage in the same study area. ${ }^{19}$ This mismatch may be due to differences between moth oviposition and larval survival on host plants. ${ }^{18,57}$ Cotton role as a sink crop for $\mathrm{H}$. armigera should be investigated throughout the season and at larger scales. Of all the host crops considered, tomato plants require particular attention, as the proportion of tomato crops in the landscape was positively related to the abundance of $H$. armigera. However, the importance of tomato should be treated with some caution because it is very heavily sprayed and was not present in 2011, only in 2012 (less than 5\% on average). To validate these results, there is a need to identify biomarkers able to detect the use by $H$. armigera of tomato plants in the landscape. Our results suggest the need for additional studies to relate larval and adult responses to landscape variables in order to allow the development of $H$. armigera regulation at the landscape scale.

\section{ACKNOWLEDGEMENTS}

This work was supported by the FSP programme (Fonds de Solidarité Prioritaire, reference 2006-43) allocated to CIRAD (the French Centre for International Cooperation in Agronomic Research for Development) by the French Ministry for Foreign Affairs (MAE). We are extremely grateful to the cotton farmers of 
Angaradébou in northern Benin for their interest in the project and for allowing us to undertake research in their fields. We would also like to thank the local cotton experts of Kandi in North Benin. Noelline Tsafack's PhD fellowship was granted by CIRAD. Monsanto
Company in St Louis, Missouri, provided laboratory facilities free of charge for gossypol analysis. We thank the anonymous reviewers for their careful reading of our manuscript and their many insightful comments and suggestions.

\section{APPENDIX A}

\section{Cultural calendar of the four major host} plants of $H$. armigera in Northern Benin

\begin{tabular}{|c|c|c|c|c|c|c|c|c|c|c|c|}
\hline Jan & Fev & March & April & May & June & July & Aug & Sept & Oct & Nov & Dec \\
\hline & & & & & & & & & & & \\
\hline & & & & & & & & $\mathbf{I}$ & & & \\
\hline
\end{tabular}

Months in the year

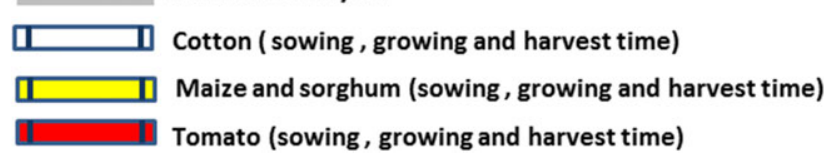

\section{APPENDIX B}

Dates of the six light trap installations in 2012 APPENDIX C

\begin{tabular}{|lccc|}
\hline & & & \\
Fields & September & October & November \\
\hline 1 & 23,30 & $14,21,28$ & 1 \\
2 & 21,26 & $3,15,21,26$ & \\
3 & 20,27 & $4,11,18,25$ & \\
4 & 24 & $1,8,15,22,29$ & \\
5 & 19,24 & $1,15,22,25$ & \\
6 & 22,27 & $4,11,18,30$ & \\
7 & 26 & $3,10,17,24,31$ & \\
8 & 18,26 & $3,14,24$ & \\
9 & 25 & $2,16,18,23,31$ & \\
10 & 22,29 & $6,13,20,27$ & \\
11 & 20,28 & $4,16,23$ & 1 \\
12 & $17,23,30$ & $6,17,24$ & 2 \\
13 & $18,22,28$ & 19,26 & \\
14 & 29 & $5,12,20,27$ & \\
15 & 25,29 & $5,12,20,27$ & \\
16 & 19,27 & $2,11,19,28$ & \\
17 & 21,28 & $5,12,26$ & \\
18 & 20,25 & $2,16,23$ & \\
19 & 21,24 & $1,14,22,29$ & \\
20 & 23,30 & $6,14,21,31$ & \\
& & & \\
\hline
\end{tabular}

\section{Dates of the two light trap installations in} 2011

\begin{tabular}{|lccc|}
\hline & & & \\
Fields & September & October & November \\
\hline 1 & 24 & 18 & \\
2 & & 4,26 & 1 \\
3 & & 10 & 3 \\
4 & & 13 & 4 \\
5 & & 23 & \\
6 & & 20,27 & \\
7 & & 3,21 & \\
8 & 28 & 14 & \\
9 & 27 & 12 & \\
10 & & 1,19 & \\
11 & & 7,25 & \\
12 & & 15,29 & \\
13 & & 11 & \\
14 & 26 & 8,24 & \\
15 & & 17 & \\
16 & 25 & & \\
17 & & & \\
\hline
\end{tabular}




\section{APPENDIX D \\ Details of the gossypol analyses}

\section{The control sample}

To determine the use of cotton as a host plant, we analysed for a gossypol derivative in moth extracts, using a liquid chromatograph/tandem mas spectrometer (LC/MS/MS). To characterise the false positive and false negative rate of this method when analysing $H$. armigera, larvae and adult moths were reared in a laboratory located in Garoua, Cameroon, using cotton bolls, tomato leaves and immature fruits, and maize flour diets. Larvae were collected directly before the pupal stage, and adult moths were collected at 1, 6 and 12 days after emergence. These control samples were randomly selected and analysed with other samples in blind tests. No false positive or negative results were detected among the 68 control samples reared on known diets (supporting information Table S1).

\section{The extraction method}

Insect samples were lyophilised prior to extraction. Individual samples were transferred into a glass vial (Xpertek, $3.1 \mathrm{~mL}$ high-recovery clear glass vial, $15 \times 45 \mathrm{~mm}$; Cobert Associates, St Louis, MO) preloaded with two glass beads ( $4 \mathrm{~mm}$; VWR, Radnor, PA). Sample vials were placed in a vibrating shaker and ground for $2 \mathrm{~min}$ at $1100 \mathrm{rpm}$. Acid hydrolysis solution $(1 \mathrm{~mL}, 1 \mathrm{~N} \mathrm{HCl}$ in methanol) was added to the vial, and vial contents were ground a second time. A quantity of $69 \mu \mathrm{L}$ of concentrated $\mathrm{NH}_{4} \mathrm{OH}$ was added to the vial, and the vial was placed in a water bath at $55^{\circ} \mathrm{C}$ for approximately $15 \mathrm{~h}$. Samples were then dried using a SpeedVac (Savant SC250EXP; Thermo Scientific, Wilmington, DE) before adding $0.8 \mathrm{~mL}$ of $0.1 \%$ formic acid in $\mathrm{H}_{2} \mathrm{O}(\mathrm{v} / \mathrm{v})$, followed by $1.5 \mathrm{~mL}$ of ethyl acetate. After shaking for $2 \mathrm{~min}$ at $1100 \mathrm{rpm}$ using a vibrating shaker, each vial was centrifuged for $10 \mathrm{~min}$ at $3000 \mathrm{rpm}$, and $1 \mathrm{~mL}$ of the ethyl acetate layer (top) was transferred into a $2 \mathrm{~mL}$ vial (Xpertek, $12 \times 32 \mathrm{~mm}$, clear glass robotic screw-thread vial; Cobert Associates). The ethyl acetate extraction was repeated, and the supernatants were combined before drying completely using a SpeedVac. The dried extract was reconstituted with $200 \mu \mathrm{L}$ of $0.1 \%$ formic acid in methanol and then transferred into a 96-well membrane filter (AcroPrep Advance 96 filter plate, $0.45 \mu \mathrm{m}$ PTFE, $350 \mu \mathrm{L}$ well; Pall Corporation, Port Washington Port) for filtration prior to injection into an LC/MS/MS.

The gossypol derivative was detected using LC/MS/MS (LC10AD pumps, Shimadzu, Kyoto, Japan; PAL autosampler, Leap Technologies, Carrboro, NC; Micromass Quattro Ultima mass spectrometer; Water, Milford, MA). The linear LC gradient was set using a mobile phase consisting of (A) $0.005 \%$ formic acid in water and (B) $0.005 \%$ formic acid in acetonitrile in the following programme: 0-1 $\min , 3-25 \%$ (B); $1-2 \mathrm{~min}, 25-40 \%$ (B); $2-2.5 \mathrm{~min}, 40-70 \%$ (B); $2.5-3.9 \mathrm{~min}, 70-80 \%$ (B); $3.9-4 \mathrm{~min}, 80-95 \%$ (B); $4-4.2 \mathrm{~min}$, $95 \%$ (B). To avoid potential cross-contamination between sample injections, a blank injection (methanol) was carried out after an insect sample injection with the following LC gradient programme: $0-0.5 \mathrm{~min}, 95 \% \quad(\mathrm{~B}) ; \quad 0.5-0.6 \mathrm{~min}, 95-3 \% \quad(B)$; 0.6-1.5 min, 3\% (B). A Gemini C18 column ( $3 \mu \mathrm{m}, 110 \AA$, $50 \times$ $2.00 \mathrm{~mm}$; Phenomenex, Torrance, $C A$ ) was used for the separation with a flow rate of $0.5 \mathrm{~mL} \mathrm{~min}{ }^{-1}$. The triple quadrupole mass spectrometer was run in MRM mode with the following acquisition parameters: precusor/product mass 517.0/470.0; dwell time $0.6 \mathrm{~s}$; collision energy $35 \mathrm{eV}$; cone voltage $50 \mathrm{~V}$; retention time $3.8 \mathrm{~min}$.

To verify the origin of the cotton marker, gossypol acetic acid (G4382; Sigma-Aldrich, St Louis, MO) was processed using the sample extraction procedure outlined above. We found the same metabolite with a mass of $m / z 517.22$ both in the final extract without moth tissue (supporting information Fig. S1 A) and in soy-fed moth tissue spiked with a gossypol acetic acid standard (data not shown). The monoisotopic mass of the resulting gossypol derivative of 518.2273 ( $\mathrm{m} / \mathrm{z} 517.22$ in negative ionisation mode) is very close to that of gossypol (518.1941, m/z 517.18 in negative ionisation mode). However, this gossypol derivative was clearly separated from gossypol in the LC/MS/MS method (supporting information Fig. S1A). The mass fragment patterns of both metabolites (supporting information Fig. S1B) suggest they are structurally related, although the identity of the structure has not yet been determined.

\section{Method characterisation}

A total of 189 moths of $H$. zea were reared on known diets, including cotton bolls, edamame (immature soybean) and corn kernels, or on an artificial diet at Monsanto's Chesterfield, Missouri, research facility. Using the data from these control moths, the two criteria for identifying a cotton positive moth were: (1) an area response of 100 or higher; (2) a signal-to-noise ratio of 5 or higher. When applying these criteria, the method detected all cotton positive moths correctly $(n=22)$, while only one false cotton positive was found among moths that were reared on known diets other than cotton $(n=167)$ (supporting information Table S2). We also tested soybean looper (SBL) Chrysodeixis includens and tobacco budworm (TBW) Heliothis virescens moths that were reared on diets including soy and cotton tissues, and found one false negative among SBL moths $(n=43)$ reared on cotton diets and one false positive among TBW moths reared on a non- cotton diet $(n=94)$. 


\section{APPENDIX E \\ Total number of individuals analysed for stable carbon isotopes $\left(C_{3} / C_{4}\right) \cdot C_{4}$ represents individuals that fed on $\mathrm{C}_{4}$ host plants (maize or sorghum), and $C_{3}$ represents individuals that fed on $\mathrm{C}_{3}$ host plants (cotton or tomato or natural vegetation or other). Twenty individuals were not assignable to any group}

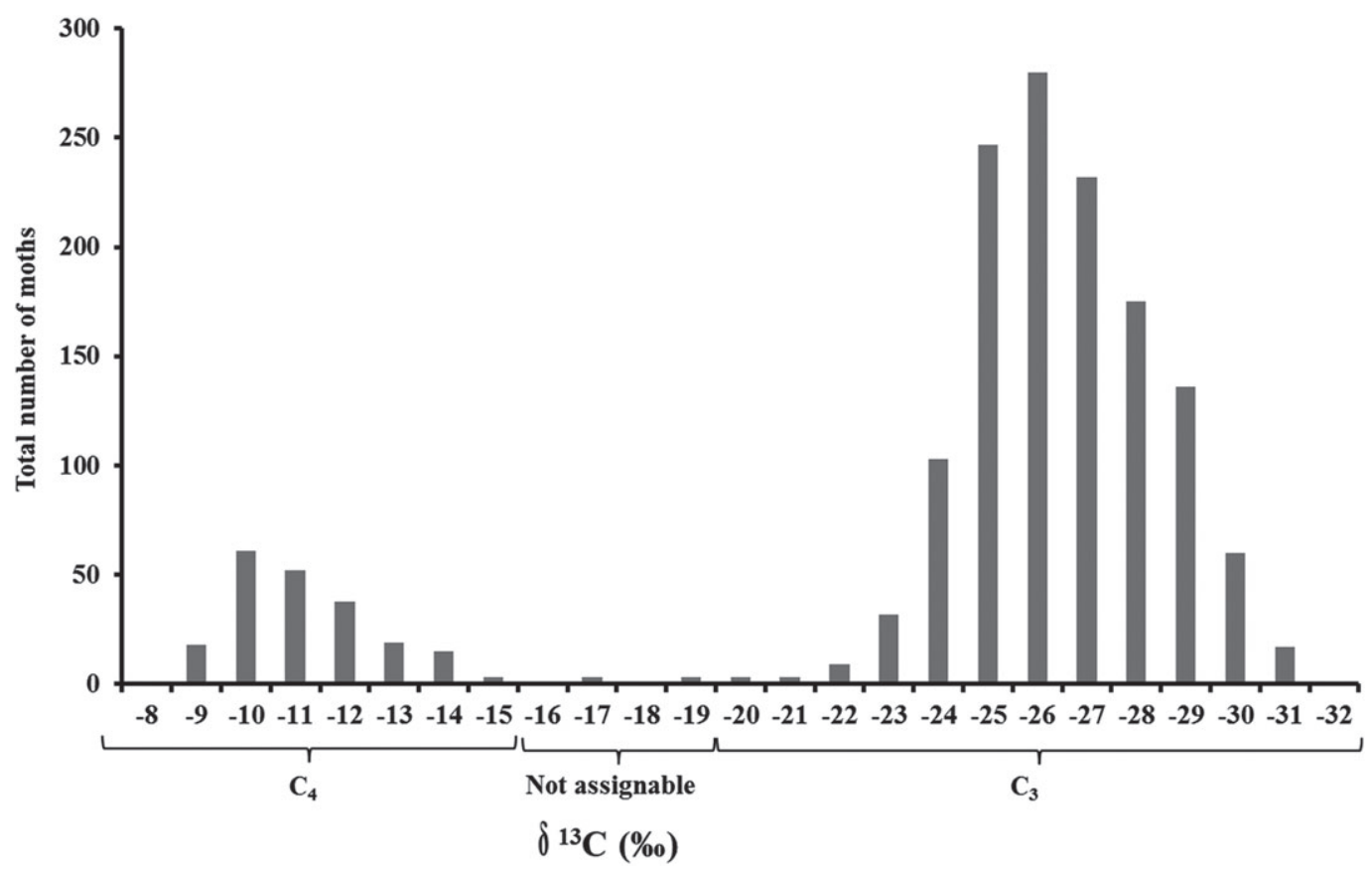

\section{SUPPORTING INFORMATION}

Supporting information may be found in the online version of this article.

\section{REFERENCES}

1 Goodell PB, Fifty years of the integrated control concept: the role of landscape ecology in IPM in San Joaquin valley cotton. Pest Manag Sci 65:1293-1297 (2009).

2 Landis DA, Wratten SD and Gurr GM, Habitat management to conserve natural enemies of arthropod pests in agriculture. Annu Rev Entomol 45:175-201 (2000).

3 Prasifka JR, Heinz KM and Minzenmayer RR, Relationships of landscape prey and agronomic variables to the abundance of generalist predators in cotton (Gossypium hirsutum) fields. Landscape Ecol 19:709-717 (2004)

4 Parry HR, Macfadyen S, Hopkinson JE, Bianchi FJJA, Zalucki MP, Bourne A et al., Plant composition modulates arthropod pest and predator abundance: evidence for culling exotics and planting natives. Basic ApplEcol 16:531 - 543 (2015)

5 Macfadyen S, Hopkinson J, Parry H, Neave MJ, Bianchi FJJA, Zalucki MP et al., Early-season movement dynamics of phytophagous pest and natural enemies across a native vegetation -crop ecotone. Agric Ecosyst Environ 200:110-118 (2015).

6 Riggi LGA, Gagic V, Bommarco R and Ekbom B, Insecticide resistance in pollen beetles over 7 years - a landscape approach. Pest Manag Sci DOI: $10.1002 / p s .4052$ (2015).

7 Bianchi FJJA, Booij CJH and Tscharntke T, Sustainable pest regulation in agricultural landscapes: a review on landscape composition, biodiversity and natural pest control. Proc R Soc Lond B 273:1715-1727 (2006).
8 Chaplin-Kramer R, O'Rourke EM, Blitzer EJ and Kremen C, A meta-analysis of crop pest and natural enemy response to landscape complexity. Ecol Lett 14:922-932 (2011).

9 Roschewitz I, Hücker M, Tscharnke T and Thies C, The influence of landscape context and farming practices on parasitism of cereal aphids. Agric Ecosyst Environ 108:218-227 (2005).

10 Rusch A, Valantin-Morison M, Roger-Estrade J and Sarthou J-P, Local and landscape determinants of pollen beetle abundance in overwintering habitats. Agric For Entomol 14:37-47 (2012).

11 Gardiner MM, Landis DA, Gratton C, Difonzo CD, O'Neal M, Chancon JM et al., Landscape diversity enhances biological control of an introduced crop pest in the north-central USA. Ecol Applic 19:143-154 (2009).

12 Letourneau DK, Armbrecht I, Rivera BS, Lerma JM, Carmona EJ, Daza MC et al., Does plant diversity benefit agroecosystems? A synthetic review. Ecol Applic 21:9-21 (2011).

13 Lu ZZ and Baker G, Spatial and temporal dynamics of Helicoverpa armigera (Lepidoptera, Noctuidae) in contrasting agricultural landscapes in northwestern China. Int J Pest Manag 59:25-34 (2013).

14 Carrière $Y$, Goodell PB, Ellers-Kirk C, Larocque G, Dutilleul P, Naranjo SE et al., Effects of local and landscape factors on population dynamics of a cotton pest. PLoS ONE 7(6):e39862 (2012).

15 Hobson AK, Wassenaar LI and Taylor OR, Stable isotopes ( $\delta \mathrm{D}$ and $\delta \mathrm{C}$ ) are geographic indicators of natal origins of monarch butterflies in eastern North America. Oecologia 120:397-404 (1999).

16 Gould F, Blair N, Reid M, Rennie TL, Lopez J and Micinski S, Bacillus thuringiensis-toxin resistance management: stable isotope assessment of alternate host use by Helicoverpa zea. Proc Natl Acad Sci USA 99:16 581 - 16586 (2002).

17 Head G, Jackson RE, Adamczyk J, Bradley JR, Van Duyn J, Gore J et al., Spatial and temporal variability in host use by Helicoverpa zea as 
measured by analyses of stable carbon isotope ratios and gossypol residues. J Appl Ecol 47:583-592 (2010).

18 Cunningham JP and Zalucki MP, Understanding heliothine (Lepidoptera: Heliothinae) pests: what is a host plant? J Econ Entomol 107:881-896 (2014).

19 Tsafack N, Menozzi P, Brevault T, Soti V, Deconchat M and Ouin A, Effects of landscape context and agricultural practices on the abundance of cotton bollworm Helicoverpa armigera in cotton fields: a case study in northern Benin. Int J Pest Manag 59:294-302 (2013).

20 Sharma HC, Strategies for pest control in sorghum in India. Trop Pest Manag 31:167-185 (1985).

21 Fefelova YA and Frolov AN, Distribution and mortality of corn earworm (Helicoverpa armigera, Lepidoptera, Noctuidae) on maize plants in Krasnodar Territory. Entomol Rev 88:480-484 (2008).

22 Johnston KA, Gatehouse JA and Anstee JH, Effects of soybean protease inhibitors on the growth and development of larval Helicoverpa armigera. J Insect Physiol 39:657-664 (1993).

23 Naseri B, Fathipour Y, Moharramipour S and Hosseininaveh V, Nutritional indices of the cotton bollworm, Helicoverpa armigera, on 13 soybean varieties. J Insect Sci 10:1 - 14 (2010).

24 Walker GP, Herman TJB, Kale AJ and Wallace AR, An adjustable action threshold using larval parasitism of Helicoverpa armigera (Lepidoptera: Noctuidae) in IPM for processing tomatoes. Biol Control 52:30-36 (2010).

25 Udamale SK, Moharil MP, Ugale TB and Mankar JM, Isolation of proteinase inhibitors from okra for inhibiting the Helicoverpa armigera (Hübner) gut proteinases. Indian J Agric Res 47:263-266 (2013).

26 Marcos TF and Rejesus RS, Population dynamics of Helicoverpa spp. in tobacco growing areas of Ilocos Norte and La Union. Philipp Entomol 8:1227-1246 (1992).

27 Nibouche S, Cycle évolutif de Helicoverpa armigera (Hübner, 1808) (Lepidoptera, Noctuidae) dans l'Ouest du Burkina Faso: biologie, écologie et variabilité géographique des populations. PhD thesis, Ecole Nationale Supérieure d'Agronomie de Montpellier, Montpellier, France (1994).

28 Achaleke J and Brévault T, Inheritance and stability of pyrethroid resistance in the cotton bollworm Helicoverpa armigera (Lepidoptera: Noctuidae) in Central Africa. Pest Manag Sci 66:137-141 (2010).

29 Rochester WA, Dillon ML, Fitt GP and Zalucki MP, A simulation model of the long-distance migration of Helicoverpa spp. Moths. Ecol Model 86:151-156 (1996).

30 Fitt GP, The ecology of Heliothis in relation to agroecosystems. Annu Rev Entomol 34:17-52 (1989).

31 Root RB, Organization of a plant-arthropod association in simple and diverse habitats: the fauna of collards (Brassica oleracea). Ecol Monogr 43:95-124 (1973).

32 Berti F, Zagbaï HS, Lebailly P and Hofs J-L, Cotton in the world, the position of African cotton and the major stakes. Biotechnol Agron Soc Environ 10:271-280 (2006).

33 Cauquil J and Vaissayre M, Principaux Ravageurs et Maladies du Cotonnier en Afrique au Sud du Sahara. Cirad/CTA. Montpellier, France, pp. $1-59$ (2000).

34 Martin T, Ochou GO, Djihito A, Traore D, Togola M, Vassal JM et al, Controlling an insecticide-resistant bollworm in West Africa. Agric Ecosyst Environ 107:409-411 (2005).

35 ArcGIS Desktop: Release 10. Environmental Systems Research Institute, Redlands, CA (2011).

36 Shannon CE, A mathematical theory of communication. AT\&T Tech $J$ 27:379-423 (1948).

37 Baker GH, Tann CR and Fitt GP, A tale of two trapping methods: Helicoverpa spp. (Lepidoptera, Noctuidae) in pheromone and light traps in Australian cotton production systems. Bull Entomol Res 101:9-23 (2011).

38 Roome RE, Activity of adult Heliothis armigera (Hb) (Lepidoptera, Noctuidae) with reference to flowering of sorghum and maize in Botswana. Bull Entomol Res 65:523-530 (1975).

39 Topper CP, Noctural behaviour of adults of Heliothis armigera (Hübner) (Lepidoptera: Noctuidae) in the Sudan Gezira and pest control implications. Bull Entomol Res 77:541-554 (1987).

40 Riley JR, Armes NJ, Reynolds DR and Smith AD, Nocturnal observations on the emergence and flight behaviour of Helicoverpa armigera (Lepidoptera: Noctuidae) in the post-rainy season in central India. Bull Entomol Res 82:243-256 (1992).

41 Ali A, Choudhury RA, Ahmad Z, Rahman F, Khan FR and Ahmad SK, Some biological characteristics of Helicoverpa armigera on chickpea. Tunisian J Plant Prot 4:99-106 (2009).
42 Brevault T, Achaleke J, Sougnabe SP and Vaissayre M, Tracking pyrethroid resistance in the polyphagous bollworm, Helicoverpa armigera (Lepidoptera: Noctuidae), in the shifting landscape of a cotton-growing area. Bull Entomol Res 98:565-573 (2008).

43 Baker GH and Tann CR, Mating of Helicoverpa armigera (Lepidoptera, Noctuidae) moths and their host plant origins as larvae within Australian cotton farming systems. Bull Entomol Res 103:171-181 (2013).

44 Le-Fu Ye, Xue Fu, Fang Ouyang, Bao-Yu Xie and Feng Ge, Determining the major $B t$ refuge crops for cotton bollworm in North China. Insect Sci 22:829-839 (2014).

45 Fortin MJ and Dale M, Spatial Analysis: A Guide for Ecologists. Cambridge University Press, Cambridge, UK, 365 pp. (2005).

46 Carrascal LM, Galván I and Gordo O, Partial least squares regression as an alternative to current regression methods used in ecology. Oikos 118:681-690 (2009).

47 Bastien P, Esposito Vinzi V and Tenenhaus M, PLS generalised linear regression. Comput Statist Data Analysis 48:17-46 (2005).

48 Tenenhaus M, La Régression PLS, Théorie et Pratique. Technip, Paris, France, pp. 127-140 (1998).

49 R: A Language and Environment for Statistical Computing. [Online]. $\mathrm{R}$ Core Team, R Foundation for Statistical Computing, Vienna, Austria (2013). Available: http://www.R-project.org/ [11 September 2015].

50 Jackson $\mathrm{HB}$ and Fahrig $\mathrm{L}$, What size is a biological relevant landscape? Landscape Ecol 27:929-941 (2012).

51 Mazzi D and Dorn S, Movement of insect pests in agricultural landscapes. Ann Appl Biol 160:97-113 (2012).

52 Schellhorn NA, Macfadyen S, Bianchi FJJA, Williams DG and Zalucki M, Managing ecosystem services in broadacre landscapes: what are the appropriate spatial scales? Aust J Exp Agric 48:1549-1559 (2008).

53 Alignier A, Raymond L, Deconchat M, Menozzi P, Monteil C, Sarthou JP et al., The effect of semi-natural habitats on aphids and their natural enemies across spatial and temporal scales. Biol Control 77:76-82 (2014).

54 Rusch A, Valantin-Morison J, Sarthou J-P and Roger-Estrade M, Multi-scale effects of landscape complexity and crop management on pollen beetle parasitism rate. Landscape Ecol 26:473-486 (2011).

55 Risch SJ, Andow D and Altieri MA, Agroecosystem diversity and pest control: data, tentative conclusions, and new research directions. Environ Entomol 12:625-629 (1983).

56 Sivakoff FS, Rosenheim JA, Dutilleul P and Carriere Y, Influence of the surrounding landscape on crop colonization by a polyphagous insect pest. Entomol Exp Applic 149:11-21 (2013).

57 Kyi A, Zalucki MP and Titmarsh IJ, An experimental study of early stage survival of Helicoverpa armigera (Lepidoptera: Noctuidae) on cotton. Bull Entomol Res 81:263-271 (1991).

58 Stephens DW, Learning and behavioral ecology: incomplete information and environmental predictability, in Insect Learning: Ecological and Evolutionary Perspectives, ed. by Papaj DR and Lewis AC. Chapman and Hall, New York, NY, pp. 195-218 (1993).

59 Cunningham JP, Jallow MFA, Wright DJ and Zalucki MP, Learning in host selection in Helicoverpa armigera (Hübner) (Lepidoptera: Noctuidae). Anim Behav 55:227-234 (1998).

60 Carriere Y, Roff DA and Deland J-P, Evolution of diapause and insecticide resistance: a test of an optimality model. Ecology 76:1497-1505 (1995).

61 Liu Z, Gong P, Li D and Wei W, Pupal diapause of Helicoverpa armigera (Hübner) (Lepidoptera: Noctuidae) mediated by larval host plants: pupal weight is important. J Insect Physiol 56:1863-1870 (2010).

62 Carrière $Y$, Dutilleul $P$, Ellers-Kirk C, Pedersen B, Haller $S$, Antilla $L$ et al., Sources, sinks, and the zone of influence of refuges for managing insect resistance to Bt crops. Ecol Applic 14:1615-1623 (2004).

63 Carrière Y, Ellsworth PC, Dutilleul P, Goodell PB, Ellers-Kirk C, Barkley $V$ et al., A GIS-based approach for areawide pest management: the scales of Lygus hesperus movements to cotton from alfalfa, weeds, and cotton. Entomol Exp Applic 18:203-210 (2006).

64 Eriksen AB, Selldén G, Skogen D and Nilsen S, Comparative analyses of the effect of triacontanol on photosynthesis, photorespiration and growth of tomato $\left(C_{3}\right.$-plant) and maize $\left(C_{4}\right.$-plant). Planta 152:44-49 (1981).

65 Ferreres F, Taveira M, Gil-Izquierdo A, Oliveira L, Teixeira T, Valen$\tan \mathrm{P}$ et al., High performance liquid chromatography diode array detection electrospray ionization multi-stage mass spectrometric screening of an insect/plant system: the case of Spodoptera littoralis/Lycopersicon esculentum phenolics and alkaloids. Rapid Commun Mass Spectrom 25:1972-1980 (2011). 